Supplement of Hydrol. Earth Syst. Sci., 22, 977-988, 2018

https://doi.org/10.5194/hess-22-977-2018-supplement

(c) Author(s) 2018. This work is distributed under

the Creative Commons Attribution 3.0 License.

(c) (1)
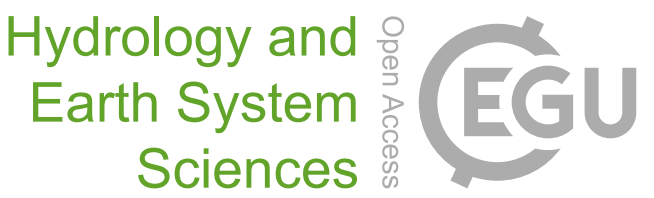

Supplement of

\title{
Hydrological characterization of cave drip waters in a porous limestone: Golgotha Cave, Western Australia
}

Kashif Mahmud et al.

Correspondence to: Kashif Mahmud (k.mahmud@westernsydney.edu.au)

The copyright of individual parts of the supplement might differ from the CC BY 3.0 License. 
Figure S1: Histogram plots of all drip sites. Each histogram represents the frequencies of the drip counts per day (The axes labels are shown in the first histogram). Bin size is uniform for all plots and the external tick marks in $\mathrm{x}$-axes delineates the bin intervals. The legend shows all the seasons over the monitoring period (blue to cyan for wet seasons: April to September and red to yellow for dry seasons: October to March, with the color gradually shifting for different years). The 2012 wet season experienced similar rainfall to the long-term annual mean, whereas 2013 was rather wet and 2014 was a relatively dry year.
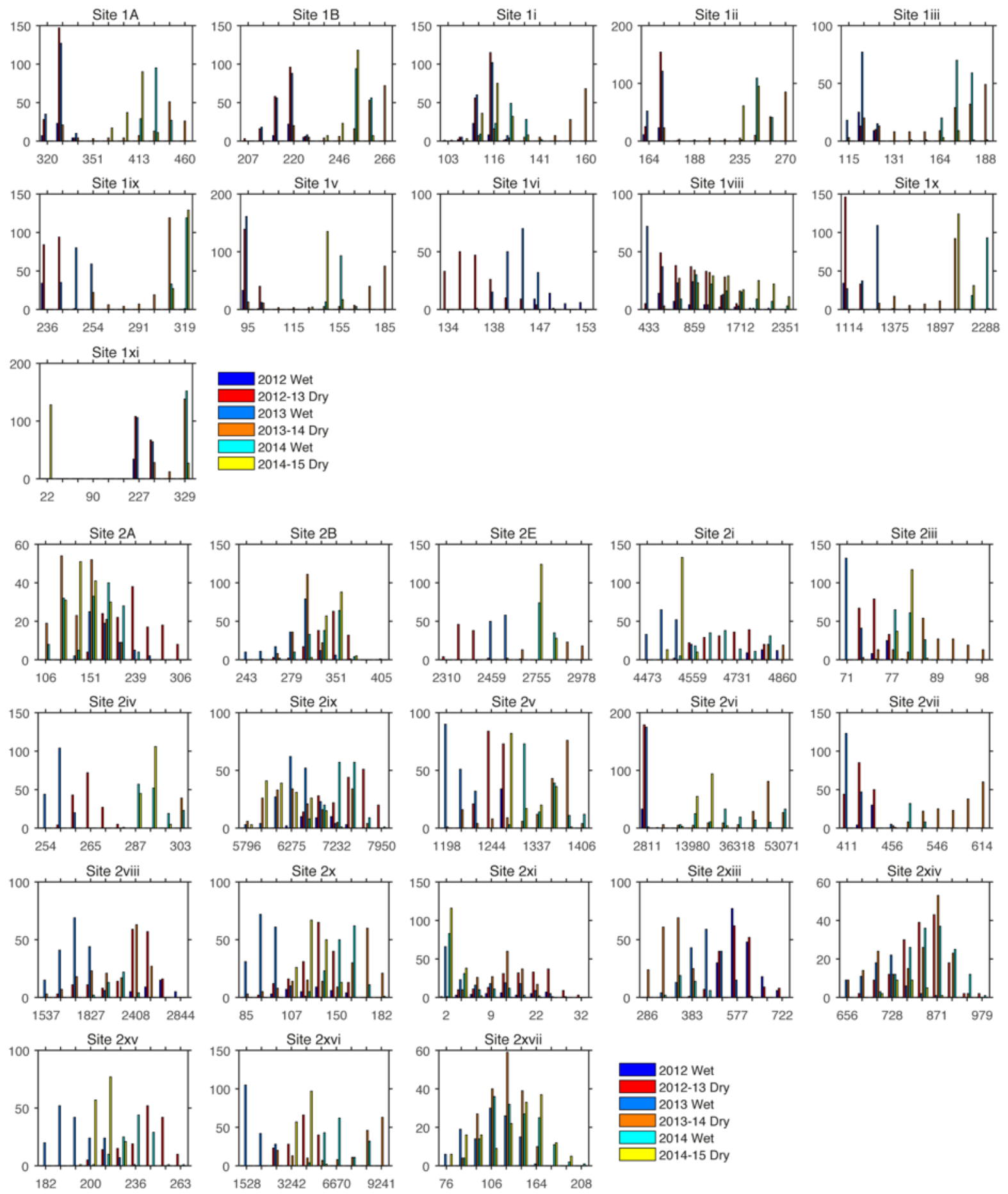
Figure S2: Autocorrelation functions of all drip sites. X- and Y-axis of individual plots represents the lag (in days) and ACF respectively (The axes labels are shown in the first ACF plot).
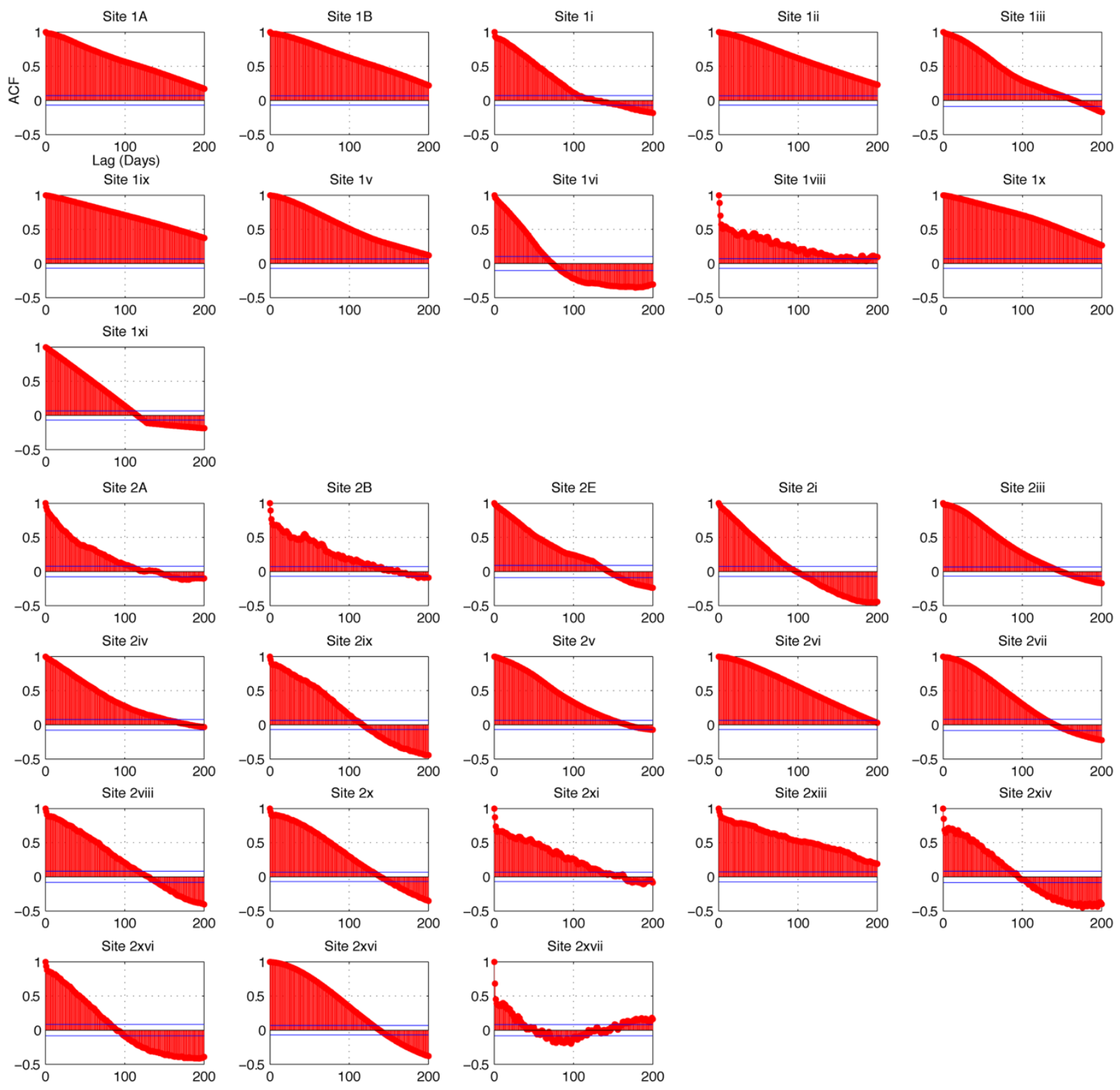